\title{
Hyperosmotic stress enhances cytotoxicity of SMAC mimetics
}

\author{
Sebastian Bittner ${ }^{1}$, Gertrud Knoll ${ }^{1}$ and Martin Ehrenschwender,
}

Inhibitors of apoptosis (IAP) proteins contribute to cell death resistance in malignancies and emerged as promising targets in cancer therapy. Currently, small molecules mimicking the IAP-antagonizing activity of endogenous second mitochondria-derived activator of caspases (SMAC) are evaluated in phase 1/2 clinical trials. In cancer cells, SMAC mimetic (SM)-mediated IAP depletion induces tumor necrosis factor (TNF) secretion and simultaneously sensitizes for TNF-induced cell death. However, tumor cells lacking SM-induced autocrine TNF release survive and thus limit therapeutic efficacy. Here, we show that hyperosmotic stress boosts SM cytotoxicity in human and murine cells through hypertonicity-induced upregulation of TNF with subsequent induction of apoptosis and/or necroptosis. Hypertonicity allowed robust TNF-dependent killing in SM-treated human acute lymphoblastic leukemia cells, which under isotonic conditions resisted SM treatment due to poor SM-induced TNF secretion. Mechanistically, hypertonicity-triggered TNF release bypassed the dependency on SM-induced TNF production to execute SM cytotoxicity, effectively reducing the role of SM to TNF-sensitizing, but not necessarily TNF-inducing agents. Perspectively, these findings could extend the clinical application of SM.

Cell Death and Disease (2017) 8, e2967; doi:10.1038/cddis.2017.355; published online 3 August 2017

Imbalances in pro- and anti-apoptotic proteins disturb cellular death pathways and allow tumor cells to escape from chemotherapy-induced apoptosis. Newer therapeutic approaches aim to reinstate the cell's death machinery by targeting the pro-survival BCL-2 family members or the cellular inhibitor of apoptosis proteins (IAP) cIAP1, clAP2 and X-linked IAP (XIAP). Mechanistically, XIAP blocks apoptosis by direct caspase inhibition whereas cIAP1/2 shut down cell death promoting activities of receptor-interacting protein kinase-1 (RIPK1). Overexpression of IAP contributes to the onset of cancer and drug resistance, ${ }^{1,2}$ which stimulated the development of SMAC mimetics (SM): small IAP-binding molecules mimicking the IAP-antagonizing activity of endogenous second mitochondria-derived activator of caspases (SMAC). SM free caspases from XIAP-mediated inhibition and trigger degradation of clAP1/2, which is death promoting in two interdependent ways: it initiates autocrine secretion of tumor necrosis factor (TNF) and concomitantly undermines the function of clAP1/2 to counteract TNF-induced TNFreceptor 1 (TNFR1)-mediated cytotoxicity. ${ }^{3-7}$ Usually, TNFR1 activation first triggers formation of a receptor-associated signaling complex (termed 'complex I'). clAP1/2-mediated ubiquitination of complex I provides a scaffold for recruitment of kinases activating the survival-promoting canonical nuclear factor kappa B (NFKB)-pathway. SM abolish complex I ubiquitination and facilitate its transition to a secondary cytosolic complex (termed 'complex II'), which can induce apoptotic and necroptotic cell death via caspase-8 and RIPK1/ RIPK3, respectively. ${ }^{8}$ How SM trigger TNF production is not fully understood, but SM-mediated loss of clAP1/2 impairs constitutive ubiquitination and subsequent proteasomal degradation of $\mathrm{NF}_{K} \mathrm{~B}$-interacting kinase (NIK). Increasing NIK levels activate the non-canonical NFKB pathway and transcription of downstream target genes such as TNF.3,4,9,10

Efficient killing by SM alone requires both autocrine TNF secretion and TNFR1-mediated cytotoxicity. ${ }^{3-7}$ Cancer cells that do not release TNF upon SM treatment are consequently resistant even though SM-mediated IAP depletion sensitizes for TNF-induced cell death. Combining SM with exogenously added TNF could overcome this limitation, but is clinically challenging due to the severe cardio-vascular side effects of the cytokine. However, aside from SM-triggered activation of the non-canonical $\mathrm{NF}_{\kappa} \mathrm{B}$ pathway, a plethora of stimuli can induce cellular TNF production. ${ }^{11}$ Here, we show that hyperosmotic stress boosts SM cytotoxicity in human and murine cells through hypertonicity-induced upregulation of TNF with subsequent initiation of apoptotic and/or necroptotic cell death. Human acute lymphoblastic leukemia (ALL) cells resisted SM treatment under isotonic conditions due to poor SM-induced TNF secretion. Under hypertonic conditions, however, SM treatment displayed a robust, TNF-dependent cytotoxicity. Mechanistically, hypertonicity-triggered TNF secretion bypassed the dependency on SM-triggered TNF production for SM cytotoxicity and reduced the role of SM to TNF-sensitizers, but not necessarily simultaneous TNF-inducers. Perspectively, our findings could extend the clinical application of SM.

\section{Results}

Hyperosmotic stress and SM synergistically kill L929 cells in a TNF-involving manner. Addition of osmotically active solutes that cannot diffuse across the cell membrane

\footnotetext{
${ }^{1}$ Institute of Clinical Microbiology and Hygiene, University Hospital Regensburg, Franz-Josef-Strauss-Allee 11, Regensburg 93053, Germany

*Corresponding author: M Ehrenschwender, Institute of Clinical Microbiology and Hygiene, University Hospital Regensburg, Franz-Josef-Strauss-Allee 11, Regensburg 93053, Germany. Tel: +49 941 9446440; Fax: +49 941 9446402; E-mail: martin.ehrenschwender@ukr.de

Received 17.3.17; revised 26.6.17; accepted 03.7.17; Edited by T Kaufmann
} 

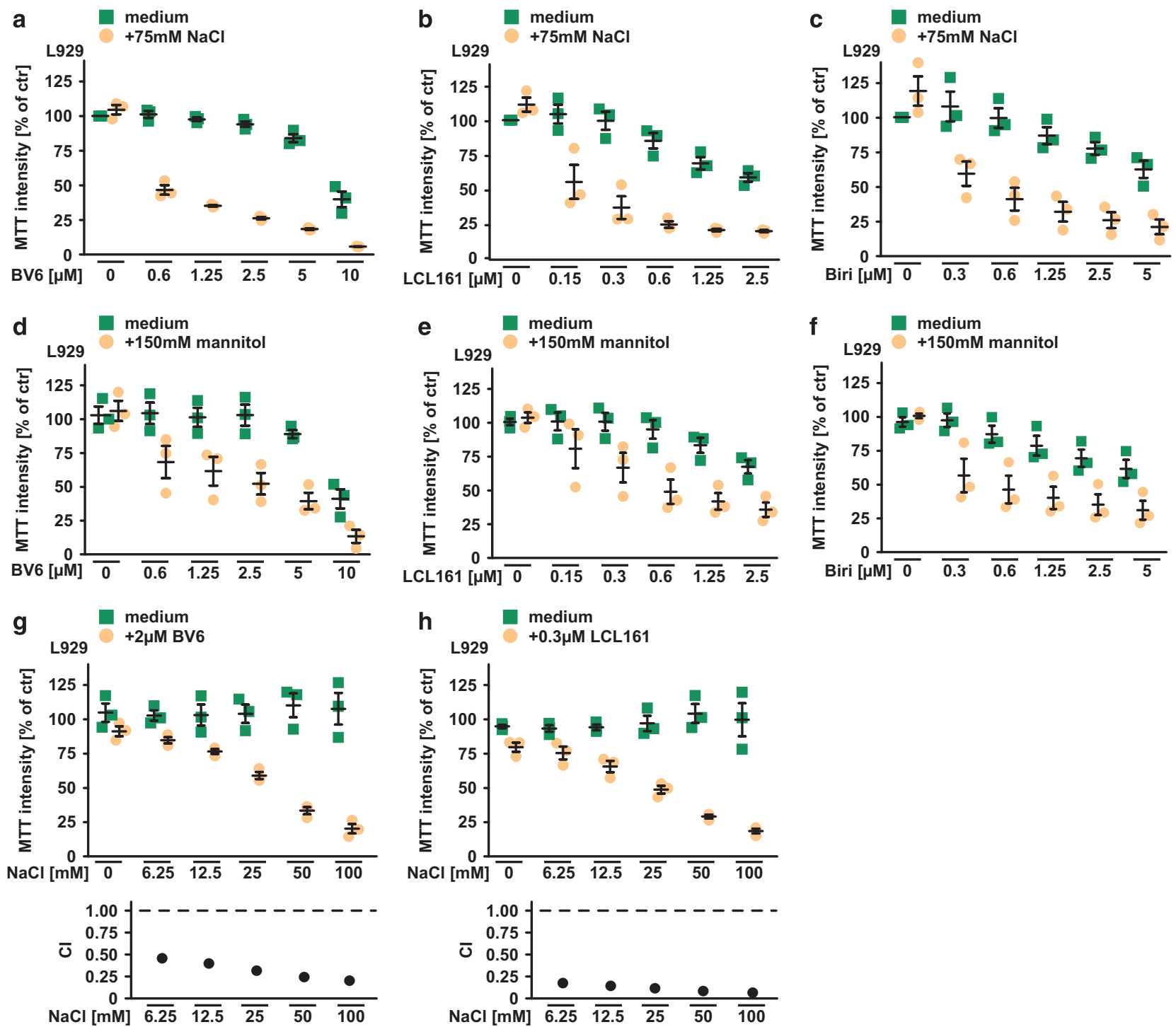

Figure 1 Hyperosmotic stress and SMAC mimetics synergistically kill L929 cells. (a-c) L929 cells were treated with the indicated concentrations of the SMAC mimetics (a) BV6, (b) LCL161 and (c) birinapant (Biri) in the presence and absence of $75 \mathrm{mM} \mathrm{NaCl}$. (d-f) Cells were treated as above, but $150 \mathrm{mM}$ mannitol was used instead of NaCl. ( $\mathbf{g}$ and $\mathbf{h}$ ) Top panel: L929 cells were challenged with the indicated concentrations of NaCl in the presence and absence of (g) $2 \mu \mathrm{M} \mathrm{BV6}$ or (h) $0.3 \mu \mathrm{M} \mathrm{LCL} 161$. Lower panel: For each combination of SMAC mimetic plus $\mathrm{NaCl}$, the corresponding combination index $(\mathrm{Cl})$ value was calculated. Cl-values $<1$ indicate a synergistic effect (see also the Materials and Methods section). Shown are data points and mean \pm S.E.M. from three independent experiments. For calculation of $\mathrm{Cl}$-values, mean values from three independent experiments were used. Biri, birinapant

(e.g. $\mathrm{NaCl}$ or mannitol) generates an osmotic pressure gradient between the intra- and extracellular space (hyperosmotic stress or hypertonicity). Hypertonicity generated by supplementing the cell culture medium with $75 \mathrm{mM} \mathrm{NaCl}$ or $150 \mathrm{mM}$ mannitol (both increasing osmolarity by $150 \mathrm{mOsm} / \mathrm{l}$ ) drastically increased cell death in L929 cells upon challenge with the SM BV6, LCL161 and birinapant compared with isotonic conditions (Figures 1a-f). Although $\mathrm{NaCl}$ alone displayed no cytotoxic effect up to a concentration of $100 \mathrm{mM}$, a gradual increase of extracellular $\mathrm{NaCl}$ was sufficient to robustly trigger cell death even when low (and under isotonic conditions marginally toxic) concentrations of BV6 and LCL161 were used (Figures $1 \mathrm{~g}$ and $\mathrm{h}$, upper panel). This pointed to a synergistic effect and was quantitatively assessed by calculating a combination index $(\mathrm{Cl})$ for BV6 and LCL161 plus $\mathrm{NaCl}$. Briefly, Cl-values $<1$ indicate a synergistic effect and decreasing $\mathrm{Cl}$-values correlate with enhanced synergism of the two compounds. ${ }^{12}$ Synergism in terms of cell death induction was observed for both, BV6 and LCL161 with $\mathrm{NaCl}$ (Figures $1 \mathrm{~g}$ and $\mathrm{h}$, lower panel). Addition of the TNF-neutralizing TNFR2-Fc fusion protein etanercept attenuated, but (especially at high SM concentrations) not fully abrogated SM cytotoxicity in the presence of $\mathrm{NaCl}$ (Figures 2a and b). This is in line with the concept that beside TNF-dependent TNFR1 activation ${ }^{3-6}$ IAP depletion can also kill cells in a TNF-independent, RIPK1-involving manner. ${ }^{13,14}$ In L929 cells, RIPK1 kinase activity is required for both, SM-triggered TNF release and TNF-mediated cell death. ${ }^{15-18}$ 

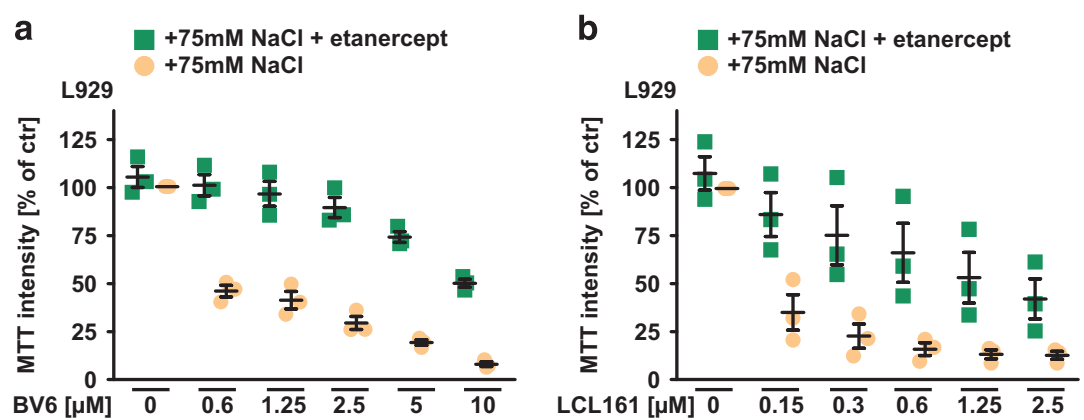

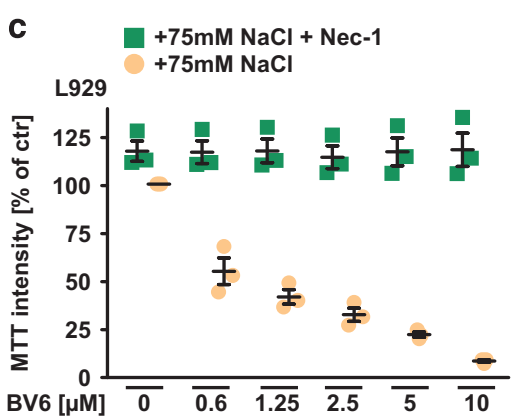

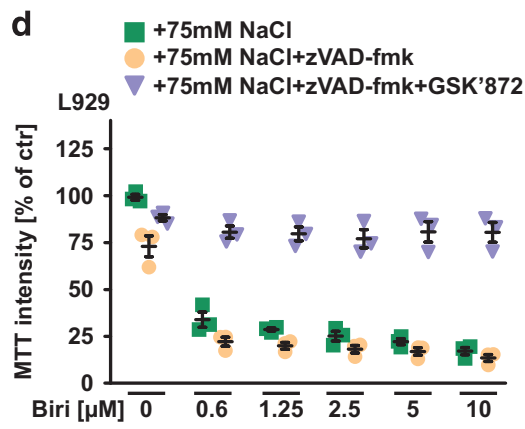

Figure 2 SMAC mimetic-induced cell death under hypertonic conditions involves TNF. (a and $\mathbf{b}$ ) L929 cells were grown in medium supplemented with $75 \mathrm{mM}$ NaCl and challenged with the indicated concentrations of (a) BV6 and (b) LCL161 in the presence and absence of etanercept ( $400 \mu \mathrm{g} / \mathrm{ml})$. (c) Cells were grown as above and treated with the indicated concentrations of BV6 in the presence and absence of $75 \mu \mathrm{M}$ necrostatin-1 (Nec-1). (d) L929 cells were grown in medium supplemented with $75 \mathrm{mM} \mathrm{NaCl}$ and challenged with the indicated concentrations of birinapant in the presence and absence of the pan-caspase inhibitor zVAD-fmk (10 $\mu \mathrm{M})$ and the RIPK3 inhibitor GSK'872 (2 $\mu \mathrm{M})$. Shown are data points and mean \pm S.E.M. from three independent experiments. Biri, birinapant

Pharmacological inhibition of RIPK1 using necrostatin-1 (Nec-1) expectedly abrogated cytotoxicity of $\mathrm{BV} 6 / \mathrm{NaCl}$ (Figure 2c). As the pan-caspase inhibitor zVAD-fmk itself induces TNF release and TNF-dependent necroptosis in L929 cells, ${ }^{15,19}$ birinapant/NaCl cytotoxicity was not reversed by zVAD-fmk alone but required additional GSK'872-mediated inhibition of necroptosis-promoting RIPK3 (Figure 2d). Collectively, these data suggested that hypertonicity enhanced SM-triggered apoptotic and/or necroptotic cell death in a TNFinvolving manner.

Hypertonicity boosts TNF-dependent apoptosis in SMAC mimetic-treated human ALL cells. Several SM are currently evaluated in clinical trials and recently encouraging results for SM-based therapies in human ALL have been reported. ${ }^{20,21}$ In human ALL cells (REH) and rhabdomyosarcoma cells (KYM-1), hypertonicity (established by addition of $50 \mathrm{mM} \mathrm{NaCl}$ or $100 \mathrm{mM}$ mannitol to the cell culture medium) enhanced BV6-, LCL161- and birinapant-mediated cytotoxicity compared with isotonic controls (Figures $3 a-c, g$ and $h$ ). Under isotonic conditions non-toxic concentrations of BV6, LCL161 and birinapant were capable to robustly kill ALL cells when the extracellular osmotic pressure was gradually increased (Figures $3 d-f$, upper panel). Calculation of the $\mathrm{Cl}$ revealed values $<1$, again indicating a synergistic mode of action for $\mathrm{SM} / \mathrm{NaCl}$ combinations (Figures $3 \mathrm{~d}-\mathrm{f}$, lower panel). Neutralizing TNF with etanercept significantly diminished SM-related cytotoxicity, demonstrating that (like in L929 cells) TNF was involved in SM-mediated killing of ALL cells facing hyperosmotic stress (Figures $4 \mathrm{a}$ and b). Notably,
SM-triggered cell death can engage the apoptotic and/or necroptotic pathway, ${ }^{22}$ but apoptosis was apparently the predominant form of cell death in $\mathrm{REH}$ cells challenged with SM plus $\mathrm{NaCl}$, as seen by (a) detection of annexin- $\mathrm{V}$ and 7-AAD in flow cytometry (Figure 4c); (b) increase of SMtriggered caspase-8 and caspase-3/-7 activation (Figures $4 d$ and e) and (c) almost full-blown rescue with the pan-caspase inhibitor zVAD-fmk (Figure 4f). In sum, these data extended our observations in L929 cells and suggested that hypertonicity and SM acted synergistically in TNF-mediated killing of human ALL cells.

SM and hypertonicity cooperate in TNF release. We next evaluated the molecular mechanism underlying $S M / N a C l$ synergism. Apparently, TNF was the key mediator for SM cytotoxicity under hypertonic conditions (Figures 2a, b, 4a and b). In L929 cells, increase in BV6- and LCL161-induced cell death under hypertonic conditions (Figures 1a and b) was paralleled by enhanced TNF secretion (Figure 5a). Similar observations were made in REH cells, which when challenged under isotonic conditions with low concentrations of SM showed minimal (BV6 and birinapant) or no detectable (LCL161) TNF release (Figure 5b). Again, hypertonicity substantially boosted SM-triggered TNF secretion (Figure 5b) and was accompanied by enhanced SM-mediated cytotoxicity (Figures $3 a-c)$. Mechanistically, this raised the question whether hyperosmotic stress simply increased TNF release initiated by $\mathrm{SM}$ via the non-canonical $\mathrm{NF}_{K} \mathrm{~B}$ pathway or itself triggered TNF production. Birinapant-induced non-canonical $\mathrm{NF} K \mathrm{~B}$ activation (as seen by decline of p100) was not 

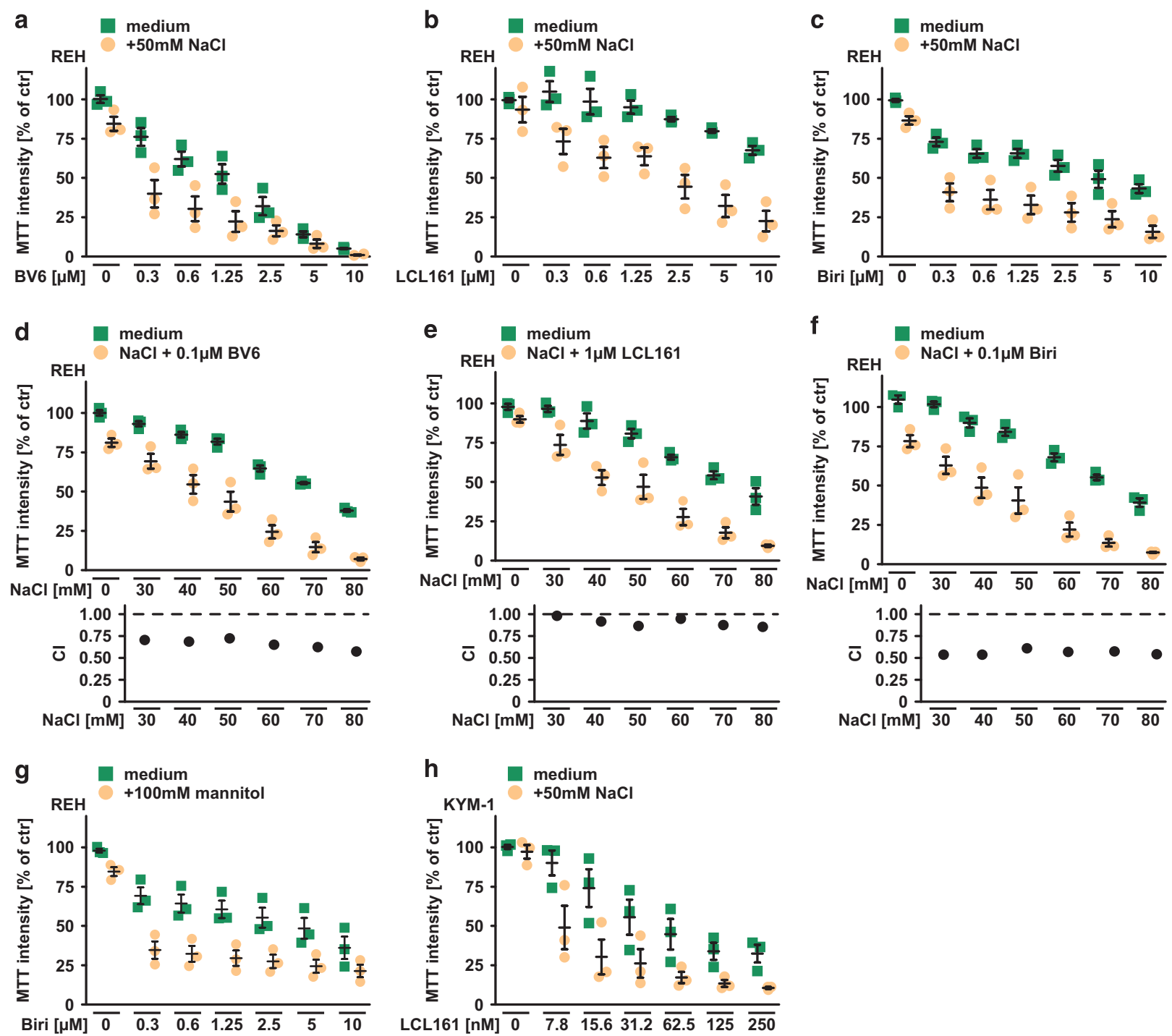

Figure 3 Hypertonicity boosts SMAC mimetic-induced cell death in human ALL cells. (a-c) REH cells were treated with the indicated concentrations of the SMAC mimetics (a) BV6, (b) LCL161 and (c) birinapant (Biri) in the presence and absence of $50 \mathrm{mM} \mathrm{NaCl}$. (d-f) Top panel: REH cells were challenged with the indicated concentrations of NaCl in the presence and absence of (a) $0.1 \mu \mathrm{M} \mathrm{BV6}$, (b) $1 \mu \mathrm{M} \mathrm{LCL161}$ or (c) $0.1 \mu \mathrm{M}$ birinapant. Shown are data points and mean \pm S.E.M. from three independent experiments. Lower panel: For each combination of SMAC mimetic plus $\mathrm{NaCl}$, the corresponding combination index (Cl) value was calculated. Cl-values $<1$ indicate a synergistic effect (see also the Materials and Methods section). Cl-values were calculated from mean values derived from three independent experiments. (g) Cells were treated as in (c), but $100 \mathrm{mM}$ mannitol was used to increase osmotic pressure. (h) KYM-1 cells were treated as in (b). Biri, birinapant

enhanced under hypertonic conditions, potentially pointing to an additional, hypertonicity-activated TNF-producing pathway (Figure 5c). This was also supported by experiments that demonstrated (a) increase of TNF levels in REH cells by $\mathrm{NaCl}$ and birinapant alone (Figure 5d); (b) NaCl-triggered TNF secretion in L929 cells without SM (Figure 5e) and (c) increased TNF mRNA levels in REH cells cultured under hypertonic conditions (Figure 5f).

TNF production under hypertonic conditions involves p38 and NFAT5. Upregulation of osmoprotective genes is a vitally important adaptive response to hyperosmotic stress and is critically dependent on the transcription factor NFAT5 (also known as TonEBP) along with its hypertonicity-induced activation through the mitogen-activated protein kinase
(MAPK) p38. ${ }^{23,24}$ Notably, NFAT5 also potently initiates TNF transcription under hyperosmotic stress. ${ }^{25}$ We observed hypertonicity-induced increase in TNF mRNA levels (Figure 5f). The notion that SM cytotoxicity under hypertonic conditions (Figures $1 \mathrm{a}-\mathrm{c}$ and $3 \mathrm{a}-\mathrm{c}$ ) was associated with higher TNF levels (Figures $5 \mathrm{a}$ and $\mathrm{b}$ ) prompted us to investigate whether the p38/NFAT5 axis could supplement SM-triggered TNF secretion. Expectedly, increased NFAT5 levels (Figure 6a) and phosphorylation of p38 and ERK (Figure 6b) were detectable in REH cells cultured under hypertonic conditions. Birinapant treatment in the presence and absence of $\mathrm{NaCl}$ significantly reduced clAP2 levels, but did not affect p38 and ERK activation. Previous reports demonstrated that p38 inhibition blocked transcriptional activity of NFAT5 and reduced NFAT5-mediated TNF 
a

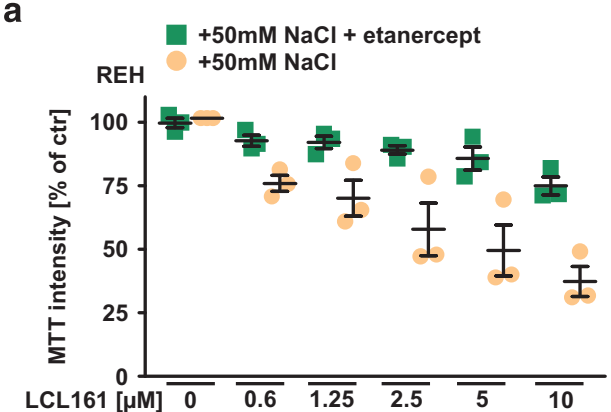

b

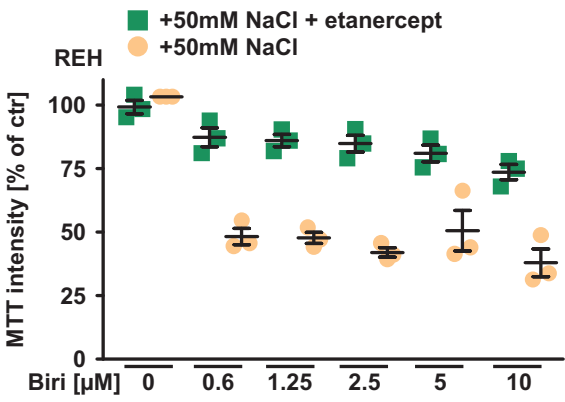

C

REH

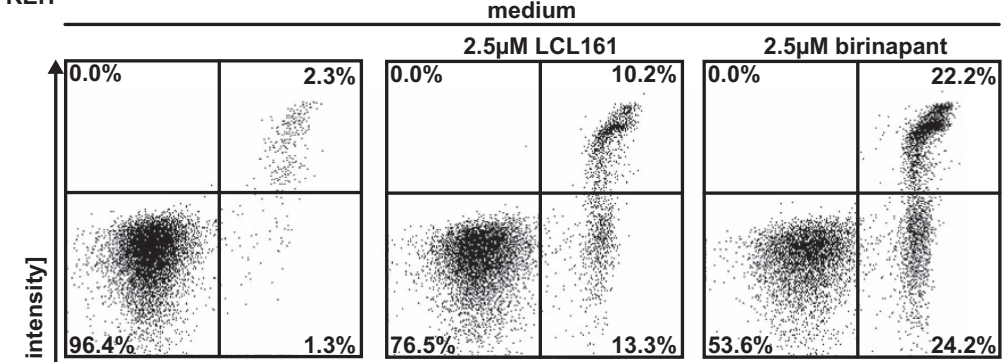

这造
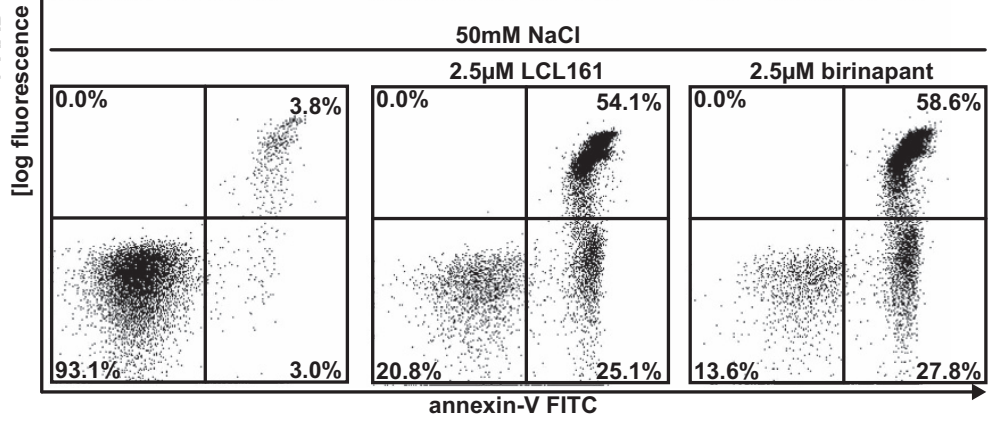

[log fluorescence intensity]
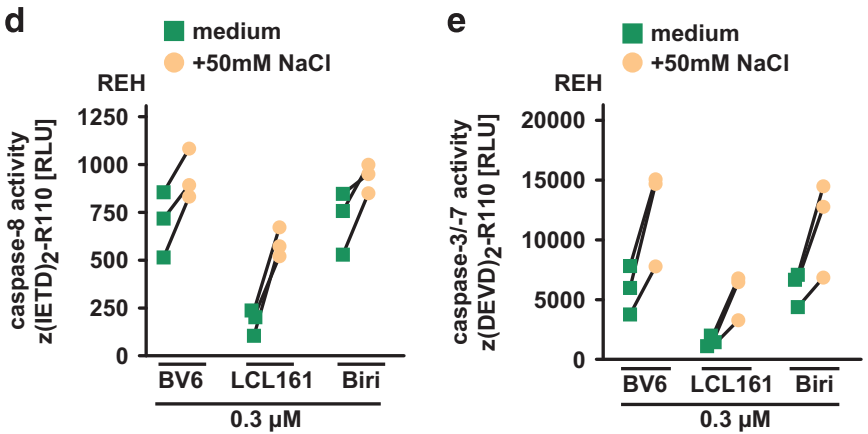

f

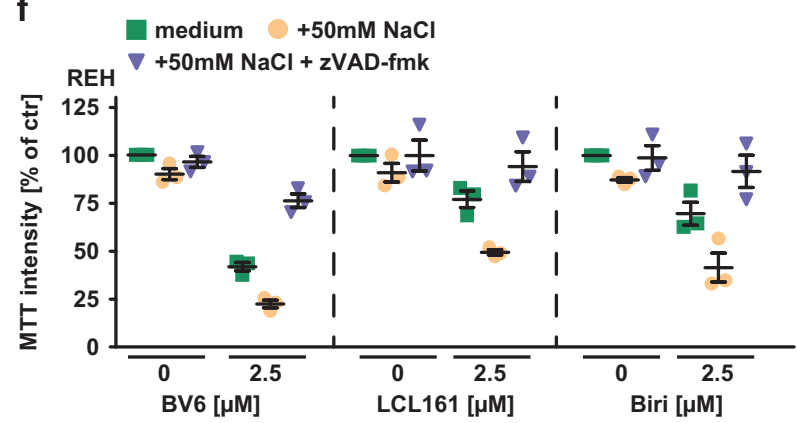

Figure 4 Hyperosmotic stress enhances SMAC mimetic-induced, TNF-mediated apoptosis in ALL cells. (a and $\mathbf{b})$ REH cells were grown in medium supplemented with $50 \mathrm{mM} \mathrm{NaCl}$ and challenged with the indicated concentrations of (a) LCL161 and (b) birinapant (Biri) in the presence and absence of etanercept (400 $\mu \mathrm{g} / \mathrm{ml})$. Shown are data points and mean \pm S.E.M. from three independent experiments. (c) REH cells were left untreated or challenged with $2.5 \mu \mathrm{M} \mathrm{LCL} 161$ or $2.5 \mu \mathrm{M}$ birinapant with or without addition of $50 \mathrm{mM} \mathrm{NaCl}$. After incubation for $16 \mathrm{~h}$, cells were analyzed by flow cytometry for positivity of 7-AAD and annexin-V. Data shown are representative of two experiments performed. (d and e) REH cells were challenged with $0.3 \mu \mathrm{M} \mathrm{BV6,} \mathrm{LCL161} \mathrm{and} \mathrm{birinapant} \mathrm{with} \mathrm{or} \mathrm{without} \mathrm{addition} \mathrm{of} 50 \mathrm{mM} \mathrm{NaCl}$ for $18 \mathrm{~h}$. Caspase-8 and caspase-3/-7 activity was assessed using the fluorogenic substrates $(\mathrm{IETD})_{2}-\mathrm{R} 110$ and $(\mathrm{DEVD})_{2}-\mathrm{R} 110$, respectively. Data points from three independent experiments are shown. $\mathrm{A}$ line connects caspase activation under isotonic conditions with the corresponding value under hypertonic conditions (50 mM NaCl) for each experiment. (f) REH cells were treated with the indicated concentrations of BV6, LCL161 and birinapant with or without addition of $50 \mathrm{mM} \mathrm{NaCl}$ and $50 \mu \mathrm{M}$ zVAD-fmk. Shown are data points and mean \pm S.E.M. from three independent experiments. Biri, birinapant

production..$^{24,26,27}$ Consequently, pharmacological inhibition of p38 under hypertonic condition should attenuate SM cytotoxicity as TNF upregulation via NFAT5 ceases. Assuming that contribution of both, SM- and hypertonicity-induced TNF production were responsible for SM cytotoxicity, we did not expect a full-blown but partial rescue when blocking only NFAT5-mediated TNF production. Indeed, the p38 inhibitors BIRB796, PH797804 and SB203580 significantly diminished hypertonicity-granted increase in SM cytotoxicity (Figures 6c-e) and (except for one outlier) decreased TNF mRNA levels under hypertonic conditions (Figure 6f). Collectively, these data suggested that triggering autocrine TNF production via hypertonicity-induced p38/NFAT5 activation was underlying synergistic cancer cell killing of $\mathrm{SM} / \mathrm{NaCl}$ combinations.
Hypertonicity-induced TNF release overcomes resistance to SM monotherapy. Thus far, we demonstrated that increased $\mathrm{SM} / \mathrm{NaCl}$ cytotoxicity is linked to enhanced autocrine TNF signaling (Figures $4 a, b$ and $5 b$ ). As single agents, SM efficacy also depends on autocrine TNF signaling combined with a concomitant 'death sensitizing' function. But most tumor entities fail to produce the critical effector cytokine TNF upon SM exposure. ${ }^{5}$ We hypothesized that hypertonicity-derived TNF could compensate for absent autocrine TNF production in SM-resistant cells and reinstate cytotoxicity of SM monotherapies. Indeed, human erythroleukemic TF-1 cells almost completely resisted even highdose treatments with the SM birinapant (Figure 7a), but SM treatment still sensitized TF-1 cells to TNF generated from nearby cells (paracrine TNF signaling). Challenging 


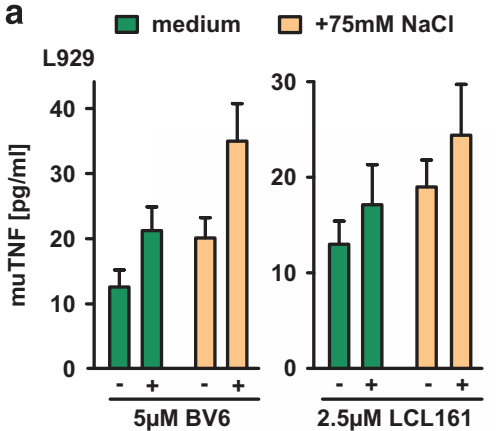

C

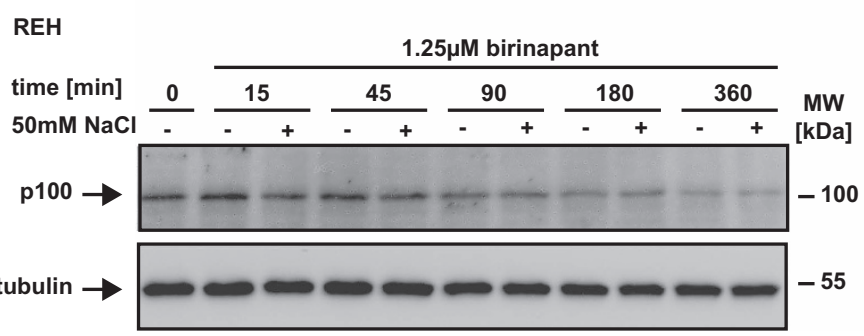

b $\square$ medium $\square+75 \mathrm{mM} \mathrm{NaCl}$

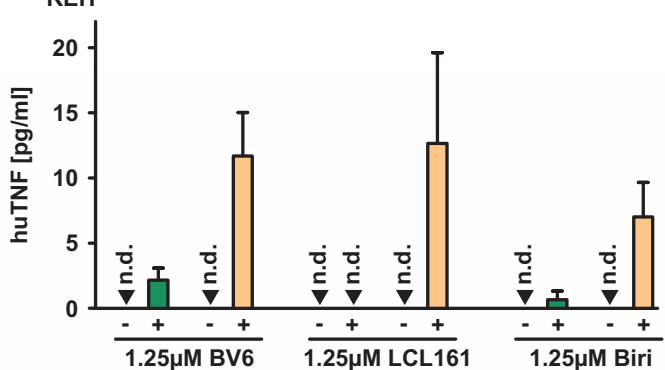

e

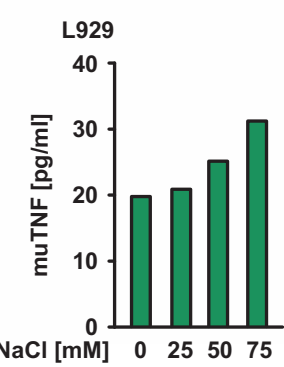

d
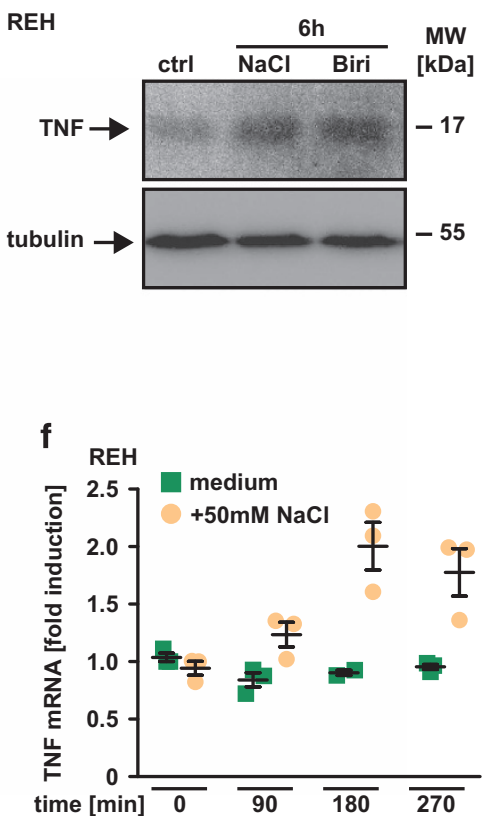

Figure 5 Hypertonicity and SMAC mimetics cooperate in autocrine TNF release. (a) L929 cells were cultured with or without addition of $75 \mathrm{mM} \mathrm{NaCl}$ and treated with the indicated concentrations of BV6 and LCL161 for $18 \mathrm{~h}$. Supernatants were collected and secretion of murine TNF was quantified using ELISA. (b) REH cells were cultured with or without addition of $50 \mathrm{mM} \mathrm{NaCl}$ and treated with the indicated concentrations of BV6, LCL161 and birinapant (Biri) for $18 \mathrm{~h}$. Secretion of human TNF in the supernatant was quantified using ELISA. Data shown for (a) and (b) are mean values \pm S.E.M. from three independent experiments. (c) REH cells were challenged with $1.25 \mu \mathrm{M}$ birinapant in the presence and absence of $50 \mathrm{mM} \mathrm{NaCl}$ for the indicated periods of time. After washing and lysis, western blot analyses were performed with antibodies specific for the indicated proteins. Detection of tubulin served as a loading control. (d) REH cells were challenged with $50 \mathrm{mM} \mathrm{NaCl}$ or $1.25 \mu \mathrm{M}$ birinapant (Biri) for $6 \mathrm{~h}$ and subsequently analyzed by western Blotting for the presence of the indicated proteins. (e) L929 cells were challenged with the indicated concentrations of NaCl for $18 \mathrm{~h}$. Secretion of murine TNF in the supernatant was quantified using ELISA. Data shown are representative of two experiments performed. (f) REH cells were challenged with $50 \mathrm{mM} \mathrm{NaCl} \mathrm{for} \mathrm{the} \mathrm{indicated}$ periods of time or left untreated. Tnf mRNA induction was analyzed by GPCR. Data points of three independent experiments together with mean \pm S.E.M. are shown. Biri, birinapant

co-cultures of 'SM-resistant' TF-1 and 'SM-responsive' REH cells with birinapant under isotonic conditions revealed a modest degree of cytotoxicity (Figure $7 b$ ), ranging expectedly between REH (Figure 3c) and TF-1 cells (Figure 7a) alone. In the presence of $50 \mathrm{mM} \mathrm{NaCl}$, however, cytotoxicity of SM was drastically increased and apparently TNF-dependent, as addition of etanercept almost completely blocked cell death (Figure 7b). This indicates that SM/ $\mathrm{NaCl}$-induced TNF release from nearby cells is sufficient to kill SM-sensitized cells that fail to activate autocrine TNF signaling. In line with this, supernatant harvested from SM/ $\mathrm{NaCl}$-challenged REH cells efficiently killed SM-sensitized TF-1 cells in a TNF-dependent manner (Figure 7c). Mechanistically, hypertonicity-induced TNF production can substitute in SM-sensitized cancer cells for lack of SM-triggered TNF release.

In sum, we demonstrate that hypertonicity-induced complementary TNF secretion via the p38/NFAT5 axis enhances SM-mediated cell death. Our work provides evidence that activation of alternative endogenous auto- or paracrine TNF sources can attenuate dependency on SM-induced TNF release for efficient cancer cell killing (summarized in Figure 8). Reducing the role of SM to TNF-sensitizing, but not necessarily TNF-inducing agents, could perspectively broaden the clinical application of SM-based therapies.

\section{Discussion}

In cancer cells, SM treatment ideally kills two birds with one stone by simultaneous production of and sensitizing to the effector molecule TNF. In most malignancies, however, SM-induced autocrine TNF production is not functional. Consequently, the response to SM monotherapy in preclinical and clinical studies has thus far been poor. ${ }^{5,18}$ Nevertheless, SM-mediated IAP depletion lowers the threshold for cell death induction. Clinical trials currently evaluate whether this is exploitable to enhance the anti-tumor activity of standard-ofcare cancer therapies. ${ }^{20}$

Alternatively, lack of SM-induced autocrine TNF secretion could be compensated by activating complementary TNFproducing pathways in cancer or other cell types in the tumor environment. For example, TNF is upregulated in response to bacterial and viral pathogen recognition by the innate immune system. Intra-vesical instillation of Bacillus Calmette-Guérin $(B C G)$ to treat early stages of bladder cancer triggered local inflammation and TNF release from recruited neutrophils. In combination with SM, neutrophil-derived TNF potently induced apoptosis. ${ }^{28}$ Additionally, oncolytic viruses synergized with SM in a TNF-dependent manner to promote tumor death in mouse models of breast cancer and glioblastoma. ${ }^{29,30}$ Cyto- and chemokine upregulation in response 

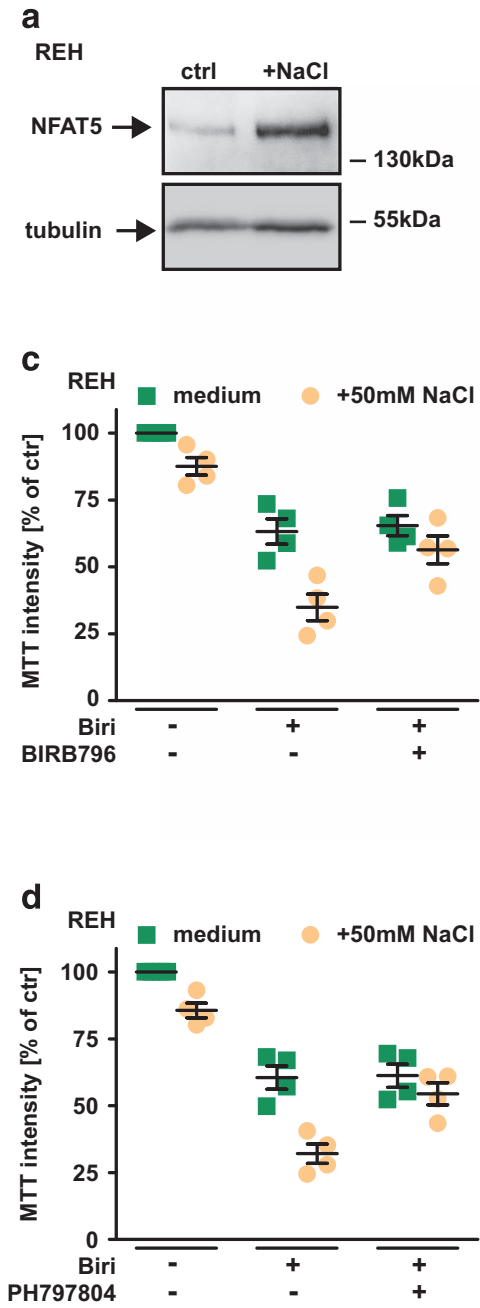

b
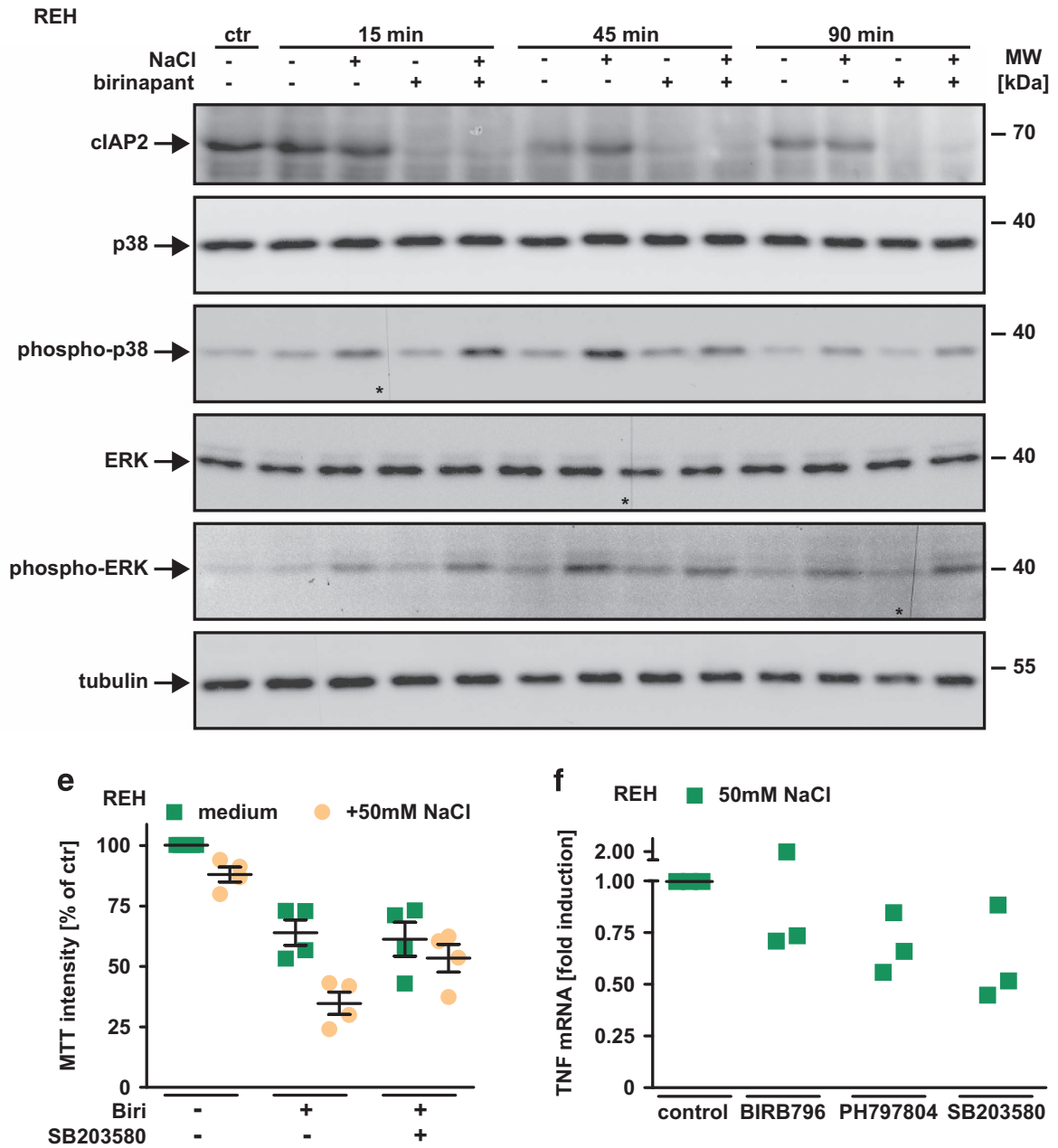

Figure 6 TNF production under hypertonic conditions involves p38 and NFAT5. (a) REH cells were cultured in the presence and absence of $50 \mathrm{mM}$ NaCl for $16 \mathrm{~h}$. Cells were washed, lysed and subsequently analyzed using western blotting with antibodies specific for the indicated proteins. (b) REH cells were challenged with $1.25 \mu \mathrm{M}$ birinapant in the presence and absence of $50 \mathrm{mM} \mathrm{NaCl}$ for the indicated periods of time. Subsequently, cells were lysed and analyzed by western blot for the indicated proteins. The asterisks ( ${ }^{*}$ ) in the phospho-p38, ERK and phospho-ERK blots indicate a defect in the CCD sensor of the western Blot imaging system. All samples were run on the same gel, no gels were sliced. (c-e) REH cells were challenged with $2.5 \mu \mathrm{M}$ birinapant under isotonic (medium) or hypertonic $(+50 \mathrm{mM} \mathrm{NaCl})$ conditions in the presence and absence of the p38 inhibitors BIRB796, PH797804 and SB203580 $(5 \mu \mathrm{M})$. Shown are data points and mean \pm S.E.M. from four independent experiments. (f) REH cells were challenged with $50 \mathrm{mM}$ $\mathrm{NaCl}$ for 210 min in the presence and absence of the p38 inhibitors BIRB796, PH797804 and SB203580 ( $5 \mu \mathrm{M})$. TnfmRNA induction was analyzed by qPCR. Data points of three independent experiments are shown. Biri, birinapant

to microbial invaders is stringently controlled and usually selflimiting. Thus, innate immune stimuli could clinically be useful to enhance cytotoxicity of SM through induction of a potent yet safe 'cytokine storm'. However, this approach might be hampered in patients suffering from leukopenia during standard-of-care chemotherapies or in patients treated with immunosuppressive drugs in the course of transplantation.

Notably, exogenous stimuli such as hyperosmotic stress can also initiate endogenous TNF production in cancer cells, ${ }^{26}$ mediated through binding of the transcription factor NFAT5 to the TNF promoter. ${ }^{25}$ Hypertonicity-induced TNF release from cancer cells (and potentially also from cells in the tumor environment) could therefore substitute for lacking SM-induced TNF production, while still relying on the TNFsensitizing activity of SM. Our study strengthened this concept by showing that hyperosmotic stress (a) initiated TNF release in human and murine cells (Figure 5), (b) enhanced SMmediated cytotoxicity in a TNF-dependent manner (Figures 1-4 and 7) and (c) efficiently killed cancer cells in combination with SM even when SM-induced TNF production was poor or absent (Figures 5 and 7). Admittedly, hypertonicity-induced increase in TNF levels might aggravate TNF-related side effects. Cytokine release syndrome, for example, has been reported as dose-limiting toxicity of systemic LCL161 administration in humans and is most likely attributable to SMinduced, NF $\kappa_{\mathrm{B}}$-mediated upregulation of pro-inflammatory cytokines (including TNF). ${ }^{31}$ However, artificially establishing (transient) hypertonic conditions in a narrowly defined area such as the tumor environment could attenuate systemic toxicity by spatially restricting TNF production and lowering SM concentrations necessary for cancer cell elimination (Figures $1 \mathrm{~g}$ and $\mathrm{h}$ and $3 \mathrm{~d}-\mathrm{f}$ ). At least in solid tumors, constant 
a

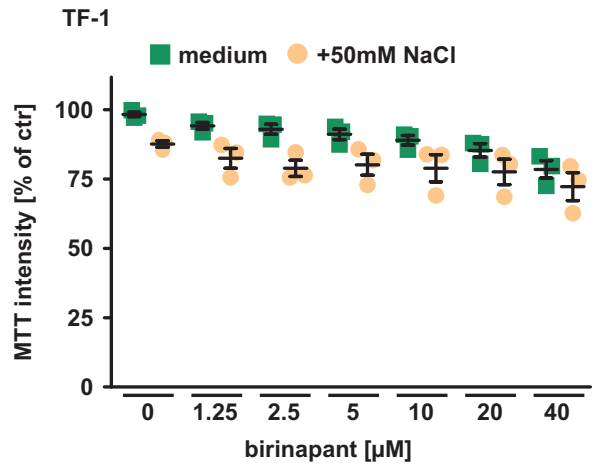

b

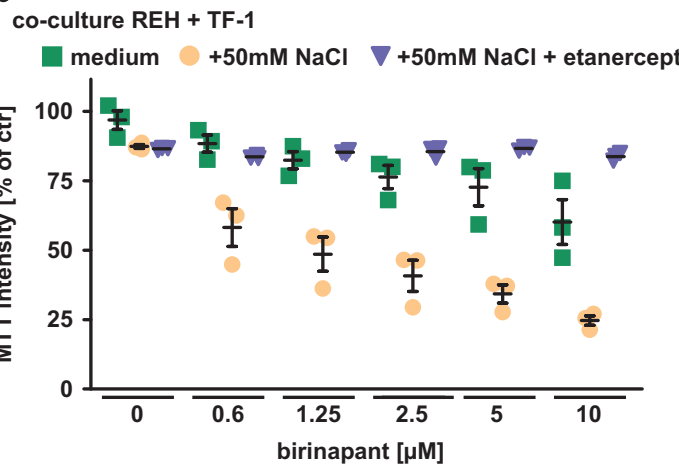

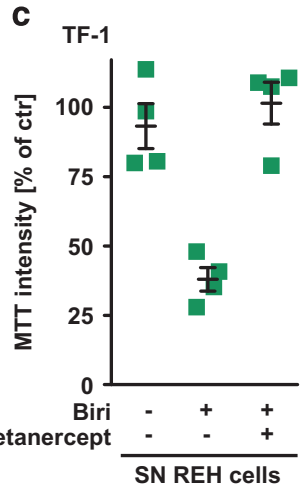

Figure 7 Hypertonicity-induced TNF release overcomes resistance to SM monotherapy. (a) TF-1 cells were challenged in the presence and absence of $50 \mathrm{mM} \mathrm{NaCl}$ with the indicated concentrations of birinapant. Shown are data points and mean \pm S.E.M. from three independent experiments. (b) Co-cultures of TF-1 and REH cells under iso- and hypertonic (+50 mM NaCl) conditions were challenged with the indicated concentrations of birinapant in the presence and absence of etanercept (1 mg/ml). Shown are data points and mean \pm S.E.M. from three independent experiments. (c) TF-1 and REH cells were challenged with $10 \mu \mathrm{M}$ birinapant in the presence of $50 \mathrm{mM} \mathrm{NaCl}$ for $18 \mathrm{~h}$ or left untreated. Supernatant of REH cells was harvested and transferred onto TF-1 cells. After $7 \mathrm{~h}$, viability of TF-1 cells was measured using MTT. Shown are data points and mean \pm S.E.M. from four independent experiments. Biri, birinapant; SN, supernatant

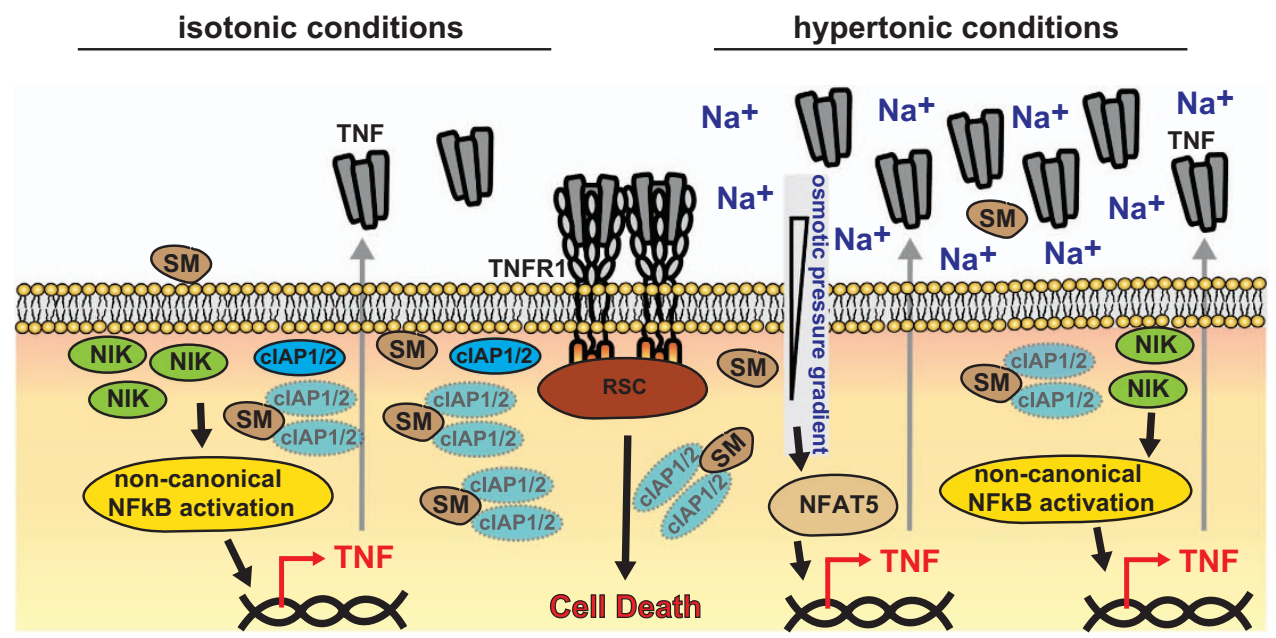

Figure 8 Hypertonicity boosts cytotoxicity of SMAC mimetics. Left side: SM trigger degradation of CIAP and thereby abolishes ubiquitination and subsequent proteasomal degradation of NIK. Increase in NIK levels results in non-canonical activation of the NFKB pathway and transcription of target genes such as TNF. In the absence of clAP1/2, autocrine TNF secretion induces cell death via TNFR1. Right side: Under hypertonic conditions, SM also deplete cIAP1/2 and enable non-canonical NF $\kappa B$ activation, TNF release and TNFR1-induced cell death. Additionally, establishing an osmotic pressure gradient activates NFAT5, a vitally important transcription factor for a cell's adaptive response to hyperosmotic stress. NFAT5 also triggers TNF transcription, which may restore SM cytotoxicity in cancer cells lacking autocrine SM-induced TNF production. RSC, receptor signaling complex

release of non-diffusible osmolytes from implantable devices (technically comparable to carmustine-releasing polymer implant wafers in malignant glioma treatment) could establish local osmotic pressure gradients and help to exert maximum SM cytotoxicity to the tumor while reducing damage in adjacent healthy tissues.

Interestingly, our results also highlight a new facet of p38 in SM cytotoxicity. A recent study elegantly demonstrated that inhibition of p38 or its downstream kinase MK2 enhanced the anti-leukemic activity of SM, essentially by increasing SMmediated TNF production. ${ }^{32}$ Hyperosmotic stress activates $\mathrm{p} 38,{ }^{33}$ raising the possibility of reduced SM cytotoxicity (due to lower TNF production) under hypertonic conditions. Our results, however, indicate the opposite. Although p38 activation was clearly detectable under hypertonic conditions
(Figure 6b), SM treatment resulted in higher TNF levels compared with isotonic controls (Figures $5 a$ and $b$ ). At a first glance, this observation seems to contradict the aforementioned study. Under hypertonic conditions, p38-dependent activation of the transcription factor NFAT5 not only upregulates osmoprotective genes ${ }^{23,24,33}$ but also TNF. ${ }^{25}$ Several studies reported reduced hypertonicity-induced TNF production upon p38 and/or NFAT5 inhibition. ${ }^{26,27,34}$ In line with this, we observed lower Tnf mRNA levels and (Figure 6f) reduced SM cytotoxicity under hypertonic conditions in the presence of p38 inhibitors (Figures 6c-e). Whether p38 activation enhances or attenuates SM cytotoxicity might therefore depend on the pathway utilized to supply the key effector molecule TNF. Whereas under isotonic conditions inhibition of p38 boosted TNF secretion by enhancing SM-induced JNK1/2 
and ERK1/2 phosphorylation, ${ }^{32}$ p38 inhibition under hypertonic conditions blunted NFAT5 activation and transcription of its target gene TNF. ${ }^{26,27,34}$ Activation of an additional endogenous TNF-producing pathway might be of special relevance in tumor cells that respond poorly to SM alone.

In sum, our data revealed that hypertonicity enhanced SM-mediated cell death by complementary TNF secretion. Activation of an alternative TNF source attenuated the dependency on SM-induced TNF release for efficient cancer cell killing (summarized in Figure 8). The tumor environment may therefore not necessarily be an unchangeable adverse determinant in cancer therapy. At least in some cancer entities, physico-chemical modulation of the tumor environment could be exploited to enhance treatment efficacy and broaden clinical application of SM-based therapies.

\section{Materials and Methods}

Cell lines, antibodies and reagents. REH (\#ACC-22), TF-1 (\#ACC334) and L929 (\#ACC-2) cells were obtained from the German Collection of Microorganisms and Cell Cultures (Braunschweig, Germany), KYM-1 cells were kindly provided by Harald Wajant (University of Wuerzburg). All cell lines were grown RPMl 1640 medium (PAN Biotech, Aidenbach, Germany) supplemented with $10 \%(\mathrm{v} / \mathrm{v})$ fetal calf serum (Sigma, Steinheim, Germany). TF-1 cells were additionally supplemented with $5 \mathrm{ng} / \mathrm{ml}$ human granulocyte-macrophage colonystimulating factor (Immunotools, Friesoythe, Germany). Antibodies used in the study: TNF \#3707, p38 \#9212, phospho-p38 \#9211, ERK \#4695, phospho-ERK \#4370 (Cell Signaling, Beverly, MA, USA); tubulin \#MS-581: Dunnlab (Asbach, Germany); NFAT5 \#PA1-023: Thermo Fisher Scientific (Waltham, MA, USA). Chemicals: MTT(3-[4,5-dimethylthiazol-2-yl]-2,5-diphenyl tetrazolium bromide): Biomol (Hamburg, Germany); zVAD-fmk (carbobenzoxy-valyl-alanyl-aspartyl(Omethyl)-fluoromethylketone): Bachem (Bubendorf, Switzerland); BIRB796, PH797804, SB203580, BV6, LCL161 and birinapant: Selleck Chemicals (Houston, TX, USA). Necrostatin-1 (Nec-1): Stress-Marq (Victoria, Canada); Etanercept was obtained from Pfizer (Berlin, Germany).

MTT-based cell viability assay. L929 $\left(2 \times 10^{4}\right.$ cells/well), REH cells $\left(7 \times 10^{4}\right.$ cells/well) and TF-1 cells $\left(7 \times 10^{4}\right.$ cells/well) were seeded in 96 -well plates and challenged with the indicated concentrations of SM in triplicates (technical replicates). For co-culture assays, 1:1 mixtures of TF- 1 and REH cells $\left(5 \times 10^{4}\right.$ cells of each cell line/well) were seeded in 96 -well plates and stimulated as above. Cell viability was determined $18 \mathrm{~h}$ after stimulation using MTT staining $\left(2 \mathrm{~h}\right.$ at $\left.37^{\circ} \mathrm{C}\right)$. Staining intensity was measured at $595 \mathrm{~nm}$ and the mean was calculated from the technical replicates of each experiment. The mean value for untreated controls was set to $100 \%$. For any other condition, the MTT staining intensity is given relative to the corresponding untreated group ( $\%$ of control). Data points shown are mean values (calculated from 3 technical replicates) of independent experiments $(n \geq 3)$.

Western blot analysis. Cells were harvested, spun down and were directly dissolved in $4 \times$ Laemmli sample buffer (8\% (w/v) SDS, 0.1 M dithiothreitol, 40\% (v/ v) glycerol, $0.2 \mathrm{M}$ Tris, pH 8.0) supplemented with phosphatase inhibitor cocktails-I and -II (Sigma). Samples were sonicated and boiled for $5 \mathrm{~min}$ at $96{ }^{\circ} \mathrm{C}$ before proteins were separated by SDS-PAGE and transferred to PVDF membranes. To block non-specific binding sites, membranes were incubated in TBS containing $0.1 \%(\mathrm{v} / \mathrm{v})$ Tween 20 and $5 \%(\mathrm{w} / \mathrm{v})$ dry milk before primary antibodies of the specificity of interest were added. Antigen-antibody complexes were visualized using horseradish peroxidase-conjugated secondary antibodies (Dako, Hamburg, Germany) and ECL technology (Pierce, Rockford, IL, USA).

Calculation of $\mathrm{Cl}$. Cl-values were calculated with the freely available software CompuSyn version 1.0 using the median effect/combination index isobologram method. ${ }^{12}$ In this model, $\mathrm{Cl}$-values $<1$ are considered to be synergistic and $\mathrm{Cl}>1$ indicate antagonistic effects. Strength of synergism can be further graded: $<0.1$ very strong synergism, 0.1-0.3 strong synergism, 0.3-0.7 synergism, 0.7-0.85 moderate synergism, $0.85-0.9$ slight synergism, $0.9-1.1$ no synergism but nearly additive effects.
Enzyme-linked immunosorbent assay. For measuring TNF secretion, L929 cells $\left(2 \times 10^{4} /\right.$ well) or REH cells $\left(1 \times 10^{6} /\right.$ well) were seeded in 96-well tissue culture plates and cultured overnight. The next day, cells were challenged with SM in the presence and absence of $\mathrm{NaCl}$. The supernatant was collected and TNF was quantified using an enzyme-linked immunosorbent assay (BD Biosciences, Heidelberg, Germany). All groups were analyzed as triplicates (technical replicates).

Caspase activity assays. Caspase activity was measured using the caspase-3/-7 and caspase-8 activity kit (AAT Bioquest, Sunnyvale, CA, USA) according to the manufacturer's instructions. Emitted fluorescence was quantified using a Victor3 Multilabel Reader (Perkin Elmer, Waltham, MA, USA).

qPCR. qPCR was essentially performed as described previously. ${ }^{35}$ In brief, total RNA was isolated using the Qiagen RNeasy mini kit (Valencia, CA, USA) according to the manufacturer's instructions. Two micrograms of total RNA were transcribed into complementary DNA using the high-capacity cDNA reverse transcription kit (Applied Biosystems, Carlsbad, CA, USA). Tnf mRNA levels were quantified using the TaqMan human Tnf (Hs00174128_m1) gene expression assay (Applied Biosystems) and an ABI Prism 7900 sequence detector (Applied Biosystems). qRTPCR reactions were performed in duplicates for each sample of an experiment and normalized to the housekeeping gene Hprt1 (Hs02800695_m1). mRNA levels were calculated using the SDS 2.1 software (Applied Biosystems).

Flow cytometry. Cell death was assessed by Annexin-V and 7-AAD staining. In brief, REH cells were challenged with $2.5 \mu \mathrm{M} \mathrm{LCL161}$ and birinapant for $16 \mathrm{~h}$ in the presence and absence of $50 \mathrm{mM} \mathrm{NaCl}$. Afterwards, cells were stained with 7-AAD and Annexin-V $\left(4^{\circ} \mathrm{C}\right.$ for $15 \mathrm{~min}$ in the dark) and analyzed immediately using a FACSCanto flow cytometer (BD Biosciences) following standard procedures.

\section{Conflict of Interest}

The authors declare no conflict of interest.

Acknowledgements. We thank Jonathan Jantsch and Patrick Neubert (University of Regensburg) for help with NFAT5 detection. ME is supported by grants from Deutsche Forschungsgemeinschaft (DFG Grant EH 465/2-1), the Roggenbuck Stiftung, the Universitätsstiftung Helga und Erwin Hartl and the Medical Faculty of the University of Regensburg (ReForM-B-program).

\section{Author contributions}

ME and SB designed the experiments; ME, SB and GK performed the experiments; $\mathrm{ME}$, GK and SB analyzed data; and ME wrote the paper.

\section{Publisher's Note}

Springer Nature remains neutral with regard to jurisdictional claims in published maps and institutional affiliations.

1. Holohan C, Van Schaeybroeck S, Longley DB, Johnston PG. Cancer drug resistance: an evolving paradigm. Nat Rev Cancer 2013; 13: 714-726.

2. Fulda S, Vucic D. Targeting IAP proteins for therapeutic intervention in cancer. Nat Rev Drug Discov 2012; 11: 109-124.

3. Vince JE, Wong WW, Khan N, Feltham R, Chau D, Ahmed AU et al. IAP antagonists target clAP1 to induce TNFalpha-dependent apoptosis. Cell 2007; 131: 682-693.

4. Varfolomeev E, Blankenship JW, Wayson SM, Fedorova AV, Kayagaki N, Garg P et al. IAP antagonists induce autoubiquitination of c-IAPs, NF-kappaB activation, and TNFalphadependent apoptosis. Cell 2007; 131: 669-681.

5. Petersen SL, Wang L, Yalcin-Chin A, Li L, Peyton M, Minna J et al. Autocrine TNFalpha signaling renders human cancer cells susceptible to Smac-mimetic-induced apoptosis. Cancer Cell 2007; 12: 445-456.

6. Gaither A, Porter D, Yao Y, Borawski J, Yang G, Donovan J et al. A Smac mimetic rescue screen reveals roles for inhibitor of apoptosis proteins in tumor necrosis factor-alpha signaling. Cancer Res 2007; 67: 11493-11498.

7. Bertrand MJ, Milutinovic S, Dickson KM, Ho WC, Boudreault A, Durkin J et al. clAP1 and cIAP2 facilitate cancer cell survival by functioning as E3 ligases that promote RIP1 ubiquitination. Mol Cell 2008; 30: 689-700.

8. Kupka S, Reichert M, Draber P, Walczak H. Formation and removal of poly-ubiquitin chains in the regulation of tumor necrosis factor-induced gene activation and cell death. FEBS J 2016; 283: 2626-2639. 
9. Vallabhapurapu S, Matsuzawa A, Zhang W, Tseng PH, Keats JJ, Wang $\mathrm{H}$ et al. Nonredundant and complementary functions of TRAF2 and TRAF3 in a ubiquitination cascade that activates NIK-dependent alternative NF-kappaB signaling. Nat Immunol 2008; 9: 1364-1370.

10. Zarnegar BJ, Wang Y, Mahoney DJ, Dempsey PW, Cheung HH, He J et al. Noncanonical NF-kappaB activation requires coordinated assembly of a regulatory complex of the adaptors CIAP1, cIAP2, TRAF2 and TRAF3 and the kinase NIK. Nat Immunol 2008; 9: 1371-1378.

11. Falvo JV, Tsytsykova AV, Goldfeld AE. Transcriptional control of the TNF gene. Curr Dir Autoimmun 2010; 11: 27-60

12. Chou TC. Theoretical basis, experimental design, and computerized simulation of synergism and antagonism in drug combination studies. Pharmacol Rev 2006; 58: 621-681.

13. Tenev T, Bianchi K, Darding M, Broemer M, Langlais C, Wallberg F et al. The Ripoptosome, a signaling platform that assembles in response to genotoxic stress and loss of IAPs. Mol Cell 2011; 43: 432-448.

14. Feoktistova M, Geserick P, Kellert B, Dimitrova DP, Langlais C, Hupe M et al. clAPs block Ripoptosome formation, a RIP1/caspase-8 containing intracellular cell death complex differentially regulated by cFLIP isoforms. Mol Cell 2011; 43: 449-463.

15. Vercammen D, Beyaert R, Denecker G, Goossens V, Van Loo G, Declercq W et al. Inhibition of caspases increases the sensitivity of $L 929$ cells to necrosis mediated by tumo necrosis factor. J Exp Med 1998; 187: 1477-1485.

16. Vanlangenakker $\mathrm{N}$, Vanden Berghe $\mathrm{T}$, Bogaert $\mathrm{P}$, Laukens $\mathrm{B}$, Zobel $\mathrm{K}$, Deshayes $\mathrm{K}$ et al. CIAP1 and TAK1 protect cells from TNF-induced necrosis by preventing RIP1/RIP3dependent reactive oxygen species production. Cell Death Differ 2011; 18: 656-665.

17. Vanlangenakker $N$, Bertrand MJ, Bogaert $P$, Vandenabeele $P$, Vanden Berghe $T$. TNF-induced necroptosis in L929 cells is tightly regulated by multiple TNFR1 complex I and II members. Cell Death Dis 2011; 2: e230.

18. Christofferson DE, Li Y, Hitomi J, Zhou W, Upperman C, Zhu H et al. A novel role for RIP1 kinase in mediating TNFalpha production. Cell Death Dis 2012; 3: e320.

19. Wu YT, Tan HL, Huang Q, Sun XJ, Zhu X, Shen HM. ZVAD-induced necroptosis in L929 cells depends on autocrine production of TNFalpha mediated by the PKC-MAPKs-AP-1 pathway. Cell Death Differ 2011; 18: 26-37.

20. Fulda S. Promises and challenges of Smac mimetics as cancer therapeutics. Clin Cancer Res 2015; 21: 5030-5036.

21. McComb S, Aguade-Gorgorio J, Harder L, Marovca B, Cario G, Eckert C et al. Activation of concurrent apoptosis and necroptosis by SMAC mimetics for the treatment of refractory and relapsed ALL. Sci Transl Med 2016; 8: 339ra370.

22. Laukens B, Jennewein C, Schenk B, Vanlangenakker N, Schier A, Cristofanon S et al. Smac mimetic bypasses apoptosis resistance in FADD- or caspase-8-deficient cells by priming for tumor necrosis factor alpha-induced necroptosis. Neoplasia 2011; 13: 971-979.

23. Miyakawa H, Woo SK, Dahl SC, Handler JS, Kwon HM. Tonicity-responsive enhance binding protein, a Rel-like protein that stimulates transcription in response to hypertonicity. Proc Natl Acad Sci USA 1999; 96: 2538-2542.

24. Ko BC, Lam AK, Kapus A, Fan L, Chung SK, Chung SS. Fyn and p38 signaling are both required for maximal hypertonic activation of the osmotic response element-binding protein/ tonicity-responsive enhancer-binding protein (OREBP/TonEBP). J Biol Chem 2002; 277: 46085-46092.
25. Esensten JH, Tsytsykova AV, Lopez-Rodriguez C, Ligeiro FA, Rao A, Goldfeld AE. NFAT5 binds to the TNF promoter distinctly from NFATp, c, 3 and 4 , and activates TNF transcription during hypertonic stress alone. Nucleic Acids Res 2005; 33: 3845-3854.

26. Lang KS, Fillon S, Schneider D, Rammensee HG, Lang F. Stimulation of TNF alpha expression by hyperosmotic stress. Pflugers Arch 2002; 443: 798-803.

27. Roth I, Leroy V, Kwon HM, Martin PY, Feraille E, Hasler U. Osmoprotective transcription factor NFAT5/TonEBP modulates nuclear factor-kappaB activity. Mol Biol Cell 2010; 21: 3459-3474.

28. Jinesh GG, Chunduru S, Kamat AM. Smac mimetic enables the anticancer action of BCG-stimulated neutrophils through TNF-alpha but not through TRAIL and FasL. J Leukoc Biol 2012; 92: 233-244.

29. Beug ST, Tang VA, LaCasse EC, Cheung HH, Beauregard CE, Brun J et al. Smac mimetics and innate immune stimuli synergize to promote tumor death. Nat Biotechnol 2014; 32: 182-190.

30. Beug ST, Beauregard CE, Healy C, Sanda T, St-Jean M, Chabot J et al. Smac mimetics synergize with immune checkpoint inhibitors to promote tumour immunity against glioblastoma. Nat Commun 2017; 8.

31. Infante JR, Dees EC, Olszanski AJ, Dhuria SV, Sen S, Cameron S et al. Phase I doseescalation study of LCL161, an oral inhibitor of apoptosis proteins inhibitor, in patients with advanced solid tumors. J Clin Oncol 2014; 32: 3103-3110.

32. Lalaoui N, Hanggi K, Brumatti G, Chau D, Nguyen NY, Vasilikos L et al. Targeting p38 or MK2 enhances the anti-leukemic activity of Smac-mimetics. Cancer Cell 2016; 29: 145-158.

33. Han J, Lee JD, Bibbs L, Ulevitch RJ. A MAP kinase targeted by endotoxin and hyperosmolarity in mammalian cells. Science 1994; 265: 808-811.

34. Lee JH, Kim M, Im YS, Choi W, Byeon SH, Lee HK. NFAT5 induction and its role in hyperosmolar stressed human limbal epithelial cells. Invest Ophthalmol Vis Sci 2008; 49: 1827-1835.

35. Siegmund D, Kums J, Ehrenschwender M, Wajant H. Activation of TNFR2 sensitizes macrophages for TNFR1-mediated necroptosis. Cell Death Dis 2016; 7: e2375.

(c) Cell Death and Disease is an open-access journal published by Nature Publishing Group. This work is licensed under a Creative Commons Attribution 4.0 International License. The images or other third party material in this article are included in the article's Creative Commons license, unless indicated otherwise in the credit line; if the material is not included under the Creative Commons license, users will need to obtain permission from the license holder to reproduce the material. To view a copy of this license, visit http://creativecommons.org/licenses/by/4.0/

(C) The Author(s) 2017 